\title{
AUTONOMÍA Y DESCONFIANZA EN «EL IMPERIO DE LA LEY» DEL PROFESOR LAPORTA
}

\author{
Juan Manuel Pérez Bermejo \\ Universidad de Salamanca
}

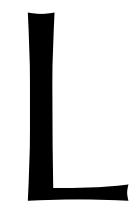

as siguientes líneas tratan de ser un homenaje y una reflexión acerca de «El imperio de la ley» de Francisco LAPORTA. Somos muchos los juristas y filósofos que podemos describir este libro como una de nuestras experiencias lectoras más sugestivas de los últimos años. A los juristas que simpatizamos con lo que se ha dado en llamar «principialismo» o «constitucionalismo», los escritos del profesor LAPORTA siempre nos han regalado momentos de sana provocación. Por concretar esta de algún modo, creo que los textos del profesor LAPORTA tienen la virtud de revelar una faz ineludible de la realidad jurídica, pero que, por distintas razones, ha sido habitualmente desdeñada o descuidada por el jurista más o menos dworkiniano. Ahora bien, constatada esta realidad, a este jurista le aguarda el desafío de integrarla dentro de una teoría o concepción del derecho muy distinta de la patrocinada por el profesor LAPORTA. Aquí es donde su provocación se revela como más saludable: ese deber de integrar las tesis del profesor LAPORTA que son correctas dentro de una concepción principialista constituye hoy uno de los desafíos teóricos más exigentes y aún no del todo satisfechos.

Sin duda, esta última idea despertaría en el profesor LAPORTA o en sus seguidores un gesto de escepticismo o de incredulidad: a su juicio, integrar cualquiera de sus tesis en una teoría principialista o constitucionalista no es un desafío o una tarea pendiente, sino una imposibilidad. El profesor LAPORTA suele identificar en el principialismo la mayor amenaza teórica que se cierne sobre sus aspiraciones acerca de cómo debería funcionar la práctica jurídica.

En estas líneas, sin embargo, no me ocupo de defender el modelo principialista de estos ataques, ni trato de demostrar por qué aquel es conciliable con los ideales de la «legalidad» que LAPORTA resume en la certeza, la seguridad y la primacía de las reglas: otros autores se han encargado ya de cumplir con estos propósitos mediante argumentos cuya formulación no podría mejorar ${ }^{1}$. En su lugar, insinuaré dos objeciones menos frecuentadas. La primera es relativa a las ideas regulativas de las que el profesor LAPORTA deduce sus conclusiones, y en concreto al valor fundacional atribuido a la

1 A modo de ejemplo, pueden leerse las críticas a LAPORTA de M. A. RODILla o J. RuIz MANERO en Certeza y predecibilidad de las relaciones jurídicas, Madrid, Fundación Coloquio Jurídico Europeo, 2009. 
autonomía (1). La segunda versa sobre el diseño institucional que surge de las ideas y exigencias que plantea, y apunta al tratamiento fuertemente asimétrico que le merecen las instituciones de legislación y de aplicación (2). El único nexo que une ambas objeciones es que estas nos permiten comparar, aunque sea de modo balbuciente, «El imperio de la ley» del profesor LAPORTA con otra de las monografías más destacables de los últimos años: Legality, del profesor S. SHAPIRO; entre ambas se percibe una sintonía y un acuerdo muy profundo en torno a sus tesis fundamentales, pero también diferencias significativas.

(1) La idea regulativa sobre la que el profesor LAPORTA construye su razonamiento es el principio moral de autonomía. Desde el punto de vista moral, el derecho debe orientarse a la autodeterminación y autorrealización de los individuos, de modo que permita y facilite la libre elección de los diferentes planes de vida o concepciones del bien con los que decidan orientar sus vidas.

La elección de esta premisa moral parece, en principio, difícilmente cuestionable: ¿qué sistema jurídico que se reconozca heredero de la Ilustración y la modernidad puede desdeñarla? Sin embargo, un primer problema es que se trata de una premisa moral «comprehensiva» en el sentido de RAWLS, porque impone condiciones al tipo de planes de vida o concepciones del bien que los individuos profesen. Es cierto que no selecciona una concepción del bien material, porque no prejuzga cuál es el modo de vida o el conjunto de doctrinas o creencias que debemos observar; sin embargo, exige una concepción del bien procedimental o de segundo grado, porque nos dice cuál es el origen moralmente válido de las concepciones del bien que debemos observar: serán moralmente válidas únicamente las concepciones que hayan surgido de nuestra elección autónoma o de las instancias a las que hayamos delegado autónomamente dicha elección. Consecuencia de este carácter comprehensivo es la mayor dificultad de hacer constitucionalmente factible un modelo político liberal. Por lo pronto, en la filosofía liberal que se asienta sobre la autonomía la neutralidad estatal vive una existencia amenazada; un Estado inspirado por ella debería favorecer un determinado origen en la formación de los planes de vida, y reconocerse obligado a utilizar sus aparatos culturales y educativos para fomentar la auto-configuración de estos por los individuos ${ }^{2}$.

Además de comprehensiva, la premisa moral de la autonomía es «fundacional». Si no interpreto mal al profesor LAPORTA, este otorga al principio de autonomía un papel axiomático o casi axiomático: es la inspiración suprema de la forma y del contenido del derecho o, como describe, «la percha» de la que cuelgan los demás conceptos normati$v^{3}{ }^{3}$. En otras palabras: LAPORTA no procede desde un conjunto de principios diversos que trate de poner en coherencia, sino que presume la existencia de un pilar fundacional seguro, como es la autonomía; otros principios como los de igualdad o trato igual poseen un estatus secundario en comparación con aquel. Sin embargo, proceder de este modo vuelve a introducir el discurso por una vía arriesgada. Por ejemplo, postular la autonomía como valor supremo impediría corregir las situaciones que atentan contra la equidad o la dignidad, pero en las que pudiera interpretarse la autorización de la supuesta víctima, como ocurriría en un hipotético consentimiento a un contrato de

\footnotetext{
${ }^{2}$ Una tesis similar se halla en B. BARrY, Justicia como imparcialidad, Barcelona, Paidós, 1997, 184 y ss.

3 El imperio de la ley, Madrid, Trotta, 2007, 37.
} 
esclavitud $^{4}$. Por supuesto, no estoy tratando de impugnar el papel de la autonomía, ni de relegarlo a un papel secundario. Solo pretendo mostrar que la autonomía no puede ser juzgada como la piedra angular o el axioma único de la filosofía moral y jurídica. Es un principio que, en la esfera pública, debe ser interpretado junto con otros principios y valores no menos importantes. Como resultado, la autonomía en la esfera política no equivale al ideal ético de la autodeterminación, sino a una idea distinta y nutrida mediante otros principios, significativamente los de equidad e imparcialidad.

Por último, mucho se podría hablar sobre el ligamen lógico entre la autonomía y los ideales de certeza y seguridad en el derecho, con el consiguiente corolario de que el derecho debe integrarse mediante leyes o reglas generales. LAPORTA es consciente de que la certeza y seguridad de las reglas son condiciones necesarias, aunque no suficientes para garantizar la autodeterminación de los individuos ${ }^{5}$. No entraré a discutir si, aun asumiendo el carácter necesariamente contributivo de la certeza y seguridad de las reglas, este es comparable al que pueden desempeñar otras razones de contenido igualmente necesarias. En torno al ligamen entre el valor fundamental de la autonomía y las ideas de certeza y seguridad, mi observación es más bien descriptiva, y no crítica. Destacaré, simplemente, lo extraño que resulta que otras contribuciones de teoría del derecho también otorguen a estas aspiraciones de certeza y seguridad en las reglas un papel fundamental, pero no necesiten de un pedestal ético o normativo que las sustente. La obra de S. SHAPIRO Legality es un buen ejemplo. Para este autor, la preferencia por reglas generales estables y obligatorias es consecuencia de detectar dos hechos sociales: a) La necesidad humana de ordenación y coordinación de la conducta. $b$ ) El remedio sugerido por la razón humana, que es y ha sido siempre el diseño de planes de conducta. El ser humano, en frases que SHAPIRO parece tomar de LAPORTA, es una «criatura planificadora ${ }^{6}$, y, en consecuencia, el derecho es un conjunto de reglas ciertas y obligatorias que nos permiten prever y coordinar nuestra conducta. Es llamativo cuando menos que estas ideas estén en LAPORTA necesitadas de compromisos morales, pero sean las que permiten a SHAPIRO liberarse de tales compromisos. Podríamos incluso abrigar la sospecha de que alguno de estos dos autores no sigue en realidad el tipo de positivismo que dice observar: si el enfoque de SHAPIRO es el que da cuenta realmente de estas ideas de certeza o legalidad, LAPORTA viajaría con un billete de positivista ético o normativo, pero en el barco más clásico del positivismo metodológico pues, de otro modo, sobrecargadas de elementos morales y políticos, sus tesis habrían naufragado; si, por el contrario, es el enfoque de LAPORTA el que presupone las ideas fundamentales de la legalidad, la asepsia o el despojamiento moral de SHAPIRO serían más bien el fotoshop con el que este habría editado su verdadera imagen: la de un positivista normativo a su pesar. En estas líneas no es posible analizar con detalle cada posición o establecer conclusiones seguras, si bien, desde mi adscripción inicial al mo-

4 Un ejemplo de aceptación de esta cláusula se halla en J. M. BuCHANAN, The Collected Works of James M. Buchanan, vol. VII, Indianapolis, Liberty Fund, 2000, 77 y 78. Podría incluso sugerirse que algunas de las causas liberales más justas, como la exigencia del sufragio universal y del voto femenino, habrían estado lejos de fortalecerse de haber basado sus reivindicaciones fundamentalmente en la autonomía: cuando KANT negaba el voto a mujeres y trabajadores, razonaba desde la autonomía, porque entendía que solo quien es «su propio señor» o sui iuris puede ser ciudadano activo. Gemeinspruch Ak-Ausg VIII, 295.

5 El imperio de la ley, op. cit., 52.

${ }^{6}$ El imperio de la ley, op. cit., 32; S. SHAPIRO, Legality, Cambridge, Harvard U.P., 2011, 119. 
delo principialista, resultará comprensible que atribuya a la segunda explicación una mayor plausibilidad que a la primera ${ }^{7}$.

(2) El segundo comentario versa sobre la teoría de la interpretación, porque en este contexto también destacan sus diferencias con Shapiro. En realidad, en el problema de la interpretación gravitan otras diferencias importantes entre ambos autores, y que de nuevo alcanzan a la comprensión particular que tiene cada uno de lo que significa la etiqueta «positivista». Así, por ejemplo, LAPORTA llega a reconocerse en algún momento heredero del formalismo jurídico ${ }^{8}$. Para SHAPIRO, sin embargo, el matrimonio entre positivismo y formalismo fue efímero; el positivismo del siglo XX, sobre todo desde las lecciones de HART, es bien consciente de las limitaciones del lenguaje de la legislación, y admite que las normas y sus términos conducen en no pocos casos a la discreción judicial ${ }^{9}$; en realidad, el último superviviente del formalismo jurídico en nuestros días sería la teoría de DwORKIN ${ }^{10}$, una compañía que no podemos presumir que LAPORTA acepte gustosamente. Podríamos extendernos sobre esta y otras diferencias que sirven de contexto a sus distintas teorías de la interpretación jurídica; es hora, sin embargo, de que concretemos por qué estas son distintas.

En la teoría de la interpretación de LAPORTA, la interpretación literal ostenta un papel hegemónico: si esta hace su trabajo y llega a una conclusión, la tarea interpretativa ha terminado. SHAPIRO, sin embargo, cree obedecer fielmente el punto de vista de HART, según el cual que cada ordenamiento sea más o menos textualista o se confíe más o menos a fines, principios y razones subyacentes es una cuestión empírica y contingente ${ }^{11}$. La pregunta que nos interroga por los métodos interpretativos que debemos cultivar en nuestra comunidad es una pregunta que nos pide una investigación de carácter meta-interpretativo, porque consistiría en una interpretación sobre los métodos de interpretación; además, nos demanda una investigación empírica, porque la respuesta a qué métodos son tenidos por correctos es relativa a una serie de hechos sociales contingentes. Ahora bien, ¿cuáles son estos hechos sociales? La respuesta de Shapiro es sencilla: el hecho social que ha de ser examinado es la confianza en las instituciones; más concretamente, debemos reconstruir la «economía de la confianza» vigente en cada comunidad, cómo se distribuye la confianza entre las distintas instituciones de dicho sistema jurídico y político. Por el hecho de asignar una serie más o menos amplia de tareas y de papeles a nuestras diversas instituciones, los diseñadores de cada sistema jurídico manifiestan una actitud distinta de confianza y de desconfianza entre, principalmente, los órganos legislativos y los órganos aplicadores del derecho. Si este diseño revela desconfianza en el poder judicial, los métodos de interpretación deben decantarse por el textualismo o literalismo; si, por el contrario, revela confianza en los

7 Interpreta a SHAPIRO como un positivista normativo encubierto, por ejemplo, T. BUSTAMANTE, «Interpreting Plans: A Critical View of Scott's Shapiro Planning Theory of Law», Australian Journal of Legal Philosophy, vol. 37, 2012.

8 F. LAPORTA, El imperio de la ley, op. cit., 191.

9 «Desde el punto de vista de HART, el pecado del formalista consiste en negar que los jueces crean a veces derecho», SHAPIRO, op. cit., 250.

${ }_{10}$ DworkIN resulta ser un formalista que le reprocha al positivismo su falta de formalismo, lo que evidencia su crítica a la discrecionalidad y su tesis de la respuesta correcta. SHAPIRO, op. cit., 261.

${ }^{11}$ Op. cit., 254. 
órganos de aplicación o incluso desconfianza en el legislador, se aceptará el recurso a fines, valores, principios y razones subyacentes ${ }^{12}$.

Creo que la teoría de la interpretación de «El imperio de la ley» resulta de un diseño institucional que se caracteriza por un reparto muy asimétrico de la confianza entre el legislador y el poder judicial. Como ya he dicho, para LAPORTA la interpretación literal es inobjetable desde el propósito o el fin de las leyes, es decir, apelando a principios o razones subyacentes. Puede que la comunidad tenga en mucho más aprecio las razones subyacentes que la interpretación literal, pero, en estos casos, no puede ceder a la tentación de permitir a sus órganos aplicadores que interpreten y apliquen sus principios de justicia, y, por servirme de una imagen que LAPORTA critica en otro contexto, debe encadenarse al mástil como Ulises frente a las sirenas ${ }^{13}$. Es preciso confiar en que un futuro legislador interprete y aplique correctamente los valores de la comunidad.

Detrás de este diseño y de este reparto de confianza subyacen cuestiones de teoría política que no puedo debatir ${ }^{14}$. En cualquier caso, creo que el diseño es extremo e incluso insólito. Que es insólito puede mostrarse históricamente si acudimos a uno de los momentos de mayor desconfianza teórica en el poder judicial: pensemos, por ejemplo, en la Francia de la primera mitad del XIX, en principio obediente a los dictados de la Escuela de la Exégesis. Sabemos, sin embargo, que la práctica jurisdiccional de aquel contexto reconstruyó numerosas figuras e instituciones al margen y a veces incluso en contra de las reglas. RECASENS, en su Nueva filosofía de la interpretación del derecho, enumeraba una lista considerable de instituciones que fueron diseñadas entonces jurisprudencialmente: el seguro de vida, la declaración de fallecimiento mediante presunción, el pago del salario a la esposa por el empresario, los deberes paternos de manutención de hijos fuera del matrimonio, etc. ${ }^{15}$ Respecto a la confianza en el legislador, la sola existencia de una segunda cámara legislativa es una prueba de que nuestro diseño y el de otros muchos Estados alimenta una mayor desconfianza que la mostrada por $E l$ imperio de la ley. Por último, LAPORTA se sirve en ocasiones del análisis económico del derecho para justificar un derecho de reglas; sin embargo, esta metodología también nos ha informado de que las lagunas, antinomias y oscuridades son muchas veces un resultado deliberado de las instituciones legislativas y, con ello, de la necesidad de

12 Paso aquí por alto los muchos problemas de la tesis de SHAPIRO. Citaré algunos a modo de ejemplo: a) la creencia ingenua en que es posible «extraer» estas actitudes de confianza o desconfianza mediante una investigación puramente empírica que no comprometa valoraciones; $b$ ) la ubicación de su teoría dentro del modelo de sistema jurídico que SHAPIRO considera habitual y ortodoxo - los sistemas «de autoridad» frente a los «oportunistas»-, pero que, a juzgar por su definición, es raramente obedecido en puridad; $c$ ) pese al empeño de SHAPIRO por distinguir entre «intérprete» y «meta-intérprete», la respuesta habitual a la pregunta «¿quién extrae el modelo de distribución de confianza del sistema jurídico y político?» solo puede atribuir esta competencia, en general, a los jueces; los jueces, de ese modo, realizarán labores constructivas, tal y como señalaba DwORKIN; d) SHAPIRO tiende a interpretar la distribución de la confianza como un plan rígido y dado de una vez por todas, como si la experiencia y los cambios en la interpretación de los principios y valores no contribuyeran en absoluto a modificarlo.

13 El imperio de la ley, op. cit., 223-224.

${ }^{14}$ A modo de ejemplo, bajo estas tesis subyace la atribución de una importancia fundamental al argumento mayoritario: las reglas emanan de instituciones elegidas democráticamente, pero los principios no, o no tanto; los diputados y senadores son elegidos mediante elecciones, pero los jueces no. Vid., p. ej., El imperio de la ley, 12.

15 L. Recasens, Nueva filosofía de la interpretación del Derecho, México, Porrúa, 1973, 196 y ss. 
atribuir una mayor responsabilidad a los órganos aplicadores ${ }^{16}$. Frente a este diseño, creo que el modelo principialista presume una distribución menos desequilibrada de la confianza: también defiende la aplicación prima facie de las reglas por razones de principio, pero confía en la posibilidad de que las instituciones aplicativas corrijan los errores más claros.

16 Es lo que ocurre cuando la negociación parlamentaria llega a un acuerdo que deja sin resolver algunos puntos socialmente conflictivos, pero el acuerdo se considera ya suficientemente beneficioso como para ser traducido en ley. Vid. F. H. EASTERBROOK, «Text, History and Structure in Statutory Interpretation», Harvard Journal of Law and Public Policy, vol. 17, 63-64. Debe admitirse sin embargo que, en estas situaciones, EASTERBROOK recomienda que los jueces «enseñen al legislador a tomarse en serio sus palabras», y a interpretar sus leyes textualmente; el autor, sin embargo, no sugiere cómo solucionar los casos de lagunas, antinomias u oscuridades. 